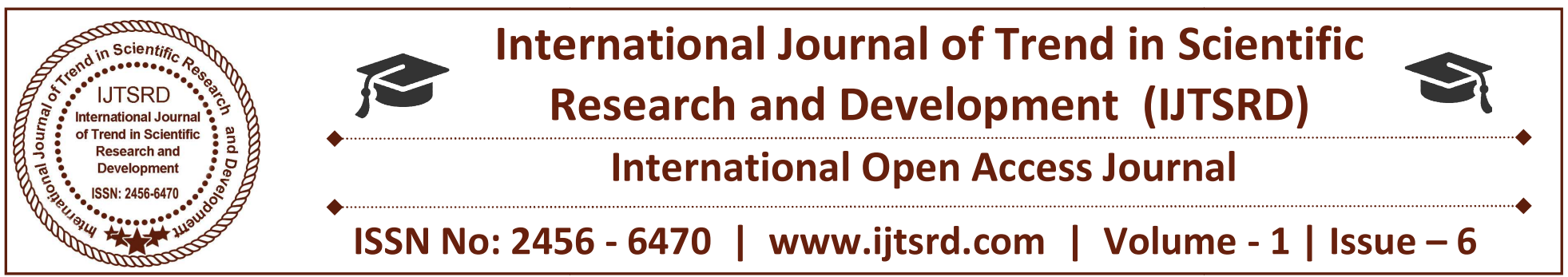

\title{
Anti-ulcer activity of some Indian Medicinal Plants against Stress Induced Gastric Ulcer in Rats
}

\author{
Lakshmi Priya.G \\ Dept of Zoology, Auxilium College, \\ Vellore, Tamil Nadu, India
}

\author{
Dr. Mary Josephine Rani.A \\ Dept of Zoology, Auxilium College, \\ Vellore, Tamil Nadu, India
}

\begin{abstract}
The antiulcer activity of the poly herbal formulation (composed of the leaf extracts from Lantana camara, Annona muricata, Kalanchoe pinnata) was evaluated in stress induced ulcer model in rats. The extract at dose of $1000 \mathrm{mg} / \mathrm{kg}$ produced significant inhibition of gastric lesion induced by above mentioned method. The extract reduced ulcerative lesion, gastric volume, free and total acidity and $\mathrm{pH}$ of gastric juice in the model. The result obtained suggesting that extract possesses significant anti-ulcer activity.
\end{abstract}

Keywords: Antiulcer, gastric lesion, Lantana camara, Annona muricata, Kalanchoe pinnata, free acidity, total acidity, ulcer index, gastric juice

\section{INTRODUCTION}

Peptic ulcer disease is one of the most common gastrointestinal disorders, which causes a high rate of morbidity particularly for the population of nonindustrialized countries (14). Peptic ulcers, also known as "ulcuspepticum" are ulcers which occur in that part of the gastrointestine (10). Several factors are implicated in the pathogenesis of gastric ulcer including increased acid-pepsin secretion, impaired bicarbonate neutralization, impaired mucus secretion and precipitate lesions on the mucosal layer $(22,16)$. In recent years, a powerful association between peptic ulcers and infection of Helicobacter pylori has been adopted. At least $70-90 \%$ of patients with gastric ulcers and $80-95 \%$ with duodenal ulcers are infected by H.pyloriand eradication of this microorganism seems to be curative for the disease (32). There is a balance between the aggressive (i.e., acid, pepsin, active oxidants, $H$. pylori) and the mucosal protective (i.e., mucus, bicarbonate, prostaglandin's) factors in stomach. Thus, drug therapy of peptic ulcer has been commonly targeted at either counteracting the aggressive factors or stimulating defensive one (54).

Gastric hyperacidity and gastroduodenal ulcer is a very common global problem today because of unhealthy eating habits, and stress. Stress, both psychological and physical is common in everyday life and is known to induce circulatory diseases and ulceration of the digestive tract (17).

Peptic ulcer is an excoriated area of the gastric or duodenal mucosa caused by action of the gastric juice. It is a chronic and recurrent disease, and is the most predominant of the gastrointestinal diseases (13). It is generally recognized that peptic ulcer is caused by a lack of equilibrium between the gastric aggressive factors and the mucosal defensive factors (44).

Peptic ulcer diseases comprise heterogeneous disorders, which manifest as a break in the lining of the gastrointestinal mucosa bathed by acid and pepsin. It is the most predominant of the gastrointestinal diseases $(19,30)$. Based on site of attack, peptic ulcermay be classified as oesophageal, duodenal, or 
gastric. The etiology of gastroduodenal ulcers is influenced by various aggressive and defensive factors such as acid-pepsin secretion, parietal cell, mucosal barrier, mucus secretion, blood flow, cellular regeneration and endogenous protective agents (prostaglandins and epidermal growth factors) (57).

Despite the progress in conventional chemistry and pharmacology in producing highly effective drugs, some of them are expensive and have different adverse effects (3). For this reason an exclusively pharmacological treatment is not always sufficient and, among other factors, nutrition plays a vital contributory or protective role.

Stress has been found to be involved in the pathogenesis of variety of states which includes muscle pain, hypertension, endocrine disorder, male infertility, peptic ulcer and gastritis. Peptic ulcer is a benign lesion of gastric or duodenal mucosa occurring at the site where the mucosal epithelium is exposed to acid and pepsin. There is always confrontation in the stomach and small intestine between acid-pepsin aggression and mucosal defense. Usually, the mucosa can withstand the acid-pepsin attack and remain healthy. That is, a mucosal 'barrier' to back diffusion of acid is maintained (23). However, an excess of acid production or an intrinsic defect in the barrier function of the mucosa can allow the defense mechanism to fail, then result into ulcer. Moreover, treatment of peptic is generally based on inhibition of gastric acid secretion by $\mathrm{H} 2$ antagonists and proton pump inhibitors such as omeprazole and antimuscarinics as well as acid-independent treatment by sucralfat and bismuth (40).

The importance of natural phenolic compounds from plants materials is also raising interest due to their redox properties which allow them to act as reducing agents, hydrogen donators and singlet oxygen quenchers. In addition, they have metal chelating properties as well $(41,4)$. Polyphenolic compounds are secondary plant metabolites found in numerous plant species and they are reported to have multiple functions to counteract the free radicals and they also inhibit different types of oxidizing enzymes (45).

Medicinal plants represent an important source of medically important compounds. Since ancient time, medicinal plants are used to cure several types of health problems. Systemic analysis of these plants provides a variety of bioactive molecules for the development of newer pharmaceutical products. Recently, there is a growing interest in the pharmacological evaluation of various plants used in different traditional system of medicine. In last few decades, many of traditionally known plants have been extensively studied by advanced scientific techniques and reported for various medicinal properties viz, anticancer activity, anti-inflammatory activity, antidiabetic activity, anthelmintic, antibacterial activity, antifungal activity, hepatoprotective activity, antioxidant activity, larvicidal activity etc $(43,26,47)$.

Lantan camara introduced in India as an ornamental plant but entirely naturalized and found throughout India. However, it is listed as one of the significant medicinal plants of the world (46). The plant Lantana camara (Verbanaceae), generally known as wild or red sage is the most widespread species of this genus and it is a woody straggling plant with various flower colors, red, pink, white, yellow and violet. It is an ever green strong smelling shrub, with stout recurred prickles, leaves opposite, ovate, acute or sub- acute, crenate -serrate, scab rid on both side (55).

\section{Scientific Classification}

Kingdom: Plantae
Order : Lamiales
Family : Verbenacea
Genus : Lantana
Species : camara

L. camara is a low erect or subscandent vigorous shrub withtetrangular stem, stout recurved pickles and a strong odourof black currents. Plant grows up to 1 to 3 meters and it canspread to 2.5 meter in width. Leaves are ovate or ovateoblong, acute or sub acute crenate serrate, rugose above,scabrid on both sides. The leaves are 3-8 cm long by 3-6 cmwide and green in colour. Leaves and stem are covered withrough hairs. Small flower held in clusters (called umbels).Colour usually orange, sometime varying from white to redin various shades and the flower usually change colours asthey ages. Flowers are having a yellow throat, in axillaryhead almost throughout the year. The calyx is small, corollatube slender, the limb spreading 6 to $7 \mathrm{~mm}$ wide anddivided in to unequal lobes. Stemen four in two pairs,included and ovary two celled, two ovuled. Inflorescencesare produced in pairs in the axils of opposite leaves. Inflorescences are compact, dome shaped 2-3 cm across and contain 20-40 sessile 
flowers. Root system is very strong and it gives out new fresh shoots even after repeated cuttings (49).

Annona muricata L. belongs to the family of Annonaceae has a widespread pantropical distribution and has been pridely known as corossol. It is a widespread small tree and has its native in Central America (1). Intensive chemical investigations of the leaves and seeds of this species have resulted in the isolation of a great number of acetogenins. The isolated compounds display some of the interesting biological or the pharmacological activities, such as antitumoral, cytotoxicity, antiparasitic and pesticidal properties. Roots of these species are used in traditional medicine due to their antiparasitical and pesticidal properties (9).

\section{Scientific Classification}

Kingdom: Plantae-Plants

Class: Magnoliopsida

Order: Magnoliales

Family: Annonaceae

Genus: Annona

Species: muricata

The genus name 'Annona' is from the Latin word 'anon', meaning 'yearly produce', referring to the fruit production habits of the various species in this genus. Annona muricata is a slender, evergreen tree, $5-10 \mathrm{~m}$ in height and $15 \mathrm{~cm}$ in diameter; trunk straight; bark smooth, dull grey or grey-brown, rough and fissured with age; inner bark pinkish and tasteless; branches at first ascending with the crown forming an inverted cone, later spreading; crown at maturity spherical due to lack of apical dominance; twigs brown or grey, bearing minute raised dots (lenticels); root system extensive and superficial, spreading beyond the diameter of the crown although shallow rooted; juvenile plants have a taproot that is eventually lost. Leaves alternate, $7.6-15.2 \mathrm{~cm}$ long, 2.5-7.6 cm wide, leathery, obovate to elliptic, glossy on top, glabrous on underside, simple; stipules absent; blade oblanceolate, green on top, paler and dull on under side with fine lateral nerves; a strong, pungent odour; petioles short, 3-10 mm long (2).

The knowledge of traditional medicine and medicinal plants and their study of scientific chemical principles may lead to the discovery of newer and cheaper drugs. Kalanchoe pinnata (Lam., syn. Bryophyllumpinnatum, B. calycinum; Local name: Pathorkuchi, Coughpatha;English name: Air plant;
Family: Crassulaceae) is an herbfound ubiquitously in Bangladesh. It has tall hollow stems,fleshy dark green leaves that are distinctly scallopedand trimmed in red, and bell-like pendulous flowers (15). Kalanchoe pinnata (K. pinnata) has become naturalizedin temperate regions of Asia, Australia, New Zealand, WestIndies, Macaronesia, Mascarenes, Galapagos, Melanesia,Polynesia, and Hawaii. It is also widely distributed in thePhilippines, where it is known as katakatakaor katakatakawhich means astonishing or remarkable (15). The leaves of $\mathrm{K}$. pinnata have a variety of uses in the traditional system of medicine in Bangladesh. They are eaten fordiabetes, diuresis, dissolving kinney stones, respiratorytract infections, as well as applied to wounds, boils, andinsect bites (15). It is useful for preventing alcoholic, viral andtoxic liver damages. The aqueous extract of this plant haveshown anti-inflammatory, anti-diabetic, anti-tumor andcutaneous leishmanicidal activities $(51,53,56,34)$.

\section{Scientific classification}

Kingdom: Plantae-Plants

Class: Magnoliopsida

Order: Saxifragales

Family: Crassulaceae stonecrop family

Genus: Kalanchoe

Species: pinnata

Kalanchoe pinnata (Family: Crassulaceae) is an important plant which has many traditional medicinal uses. Kalanchoe pinnata (Family: Crassulaceae) is an erect, succulent, perennial shrub that grows about 1.5 $\mathrm{m}$ tall and reproduces through seeds and also vegetatively from leaf bubils. It has a tall hollow stems, freshly dark green leaves that are distinctively scalloped and trimmed in red and dark bell-like pendulous flowers. This plant can easily be propagated through stems or leaf cutting. It is an introduced ornamental plant that is now growing as a weed around plantation crop. K. pinnata is used in ethnomedicine for the treatment of earache, burns, abscesses, ulcers, insect bites, whitlow, diarrhoea and cithiasis (38). In traditional medicine, Kalanchoe species have been used to treat ailments such as infections, rheumatism, and inflammation (35) and have immunosuppressive effect as well (31).

\section{MATERIALS AND METHODS}

\section{Collection and Extraction of The Plant}


The leaves of L.camara, A.muricata and K.pinnatum were collected around Vellore district. After washing the plant with running water, the leaves were separated and dried in shade for 20 days at room temperature. After shade drying, the leaves were grinded through blender and converted into coarse of powder. The powder was extracted by continuous hot extraction using the Soxhlet apparatus. The extracts were collected and preserved in a desiccator until used for further studies.

\section{Test Animal}

Adult healthy wistar rats weighting $150 \mathrm{~g}$ were used and kept in the animal house. The animals were kept in plastic cages $(34 \times 47 \times 18 \mathrm{~cm} 3)$ at animal house, in an air conditioned environment with four rats in each cage and maintained at room temperature of $(25$ $\pm 2)$ _C with relative humidity $(60 \% \pm 10 \%)$ under 12 $\mathrm{h}$ night and light cycle. The animals used for the experiment were approved by animal ethics committee.

\section{Preparation and Dose of the Test Drug}

The dose of the test drug was calculated by the method of Miller and Tainter (1944) (33), found to be $1000 \mathrm{mg} / \mathrm{kg}$ the dose of the extract was calculated with reference, the aqueous extract of the drug was used in the dose of $150 \mathrm{mg} / \mathrm{kg}$. Standard drug, Rabeprazole (Manufactured in India by Cipla Laboratories Ltd.) was used in the dose of $20 \mathrm{mg} / \mathrm{kg}$.

\section{Phytochemical analysis}

The preliminary phytochemical analysis of L.camara, A.muricata, K.pinnataleaves aqueous extract was carried out for carbohydrate, saponins, flavonoids, triterpenoids, tanins and alkaloids.

\section{Acute Toxicity Study}

The oral acute toxicity study of aqueous extract of L.camara, A.muricata, K.pinnatum Were evaluated according to Organization for Economic Cooperation and Development (OECD) guideline 420 on wistar rats, where the limit test dose of $1000 \mathrm{mg} / \mathrm{kg}$ was used. All the animals were kept at overnight fasting before to every experiment with free excess to water. The test drug was administered and observed for 14 days to determine urea, creatinine, SGOT, SGPT level.

\section{EXPERIMENTAL DESIGN}

The rats were randomly divided into 6 groups, of 4 rats each as follows:

Group-I: Control group animals received no treatment.

Group-II: animals were immersed in cold water (Negative control).

Group-III: animals received $1000 \mathrm{mg} / \mathrm{kg}$ body weight of freshly prepared L.camara.

Group-IV: animals received $1000 \mathrm{mg} / \mathrm{kg}$ bodyweight of freshly prepared A.muricata.

Group-V: animals received $1000 \mathrm{mg} / \mathrm{kg}$ body weight of freshly prepared K.pinnatum.

Group-VI: animals received $20 \mathrm{mg} / \mathrm{kg}$ body weight of Rabeprazole.

All treatments were administered orally for 11 days. Score of mucosal damage were microscopically observed.

\section{Histological observation}

In the $11^{\mathrm{t}} \mathrm{h}$ day, after $24 \mathrm{~h}$ fasting the animals were sacrificed and stomach of each animal was opened along the greater curvature. Specimens of the gastric tissue were fixed in $10 \%$ buffered formalin and were processed in the paraffin tissue-processing machine. Sections of the stomach were sectioned at $5 \mu \mathrm{m}$ and stained with hematoxylin and eosin for histological evaluation (21). Paraffin sections were stained with toluidine blue. The effect of drugs was evaluated through assessment of inflammatory and necrotic changes in the mucosal tissue.

\section{Immersion of Cold Restrained Stress}

Before ulcer induction animals of both control and experimental groups kept separately in standard controlled conditions were fasted for $24 \mathrm{~h}$ with free access to water. Acute gastric ulcers were induced by immersion of cold water and rats were sacrificed after $4 \mathrm{~h}$ of stress induced. The control group received the vehicle only, whereas the experimental group immersed in cold water for gastric ulceration. After 4 $\mathrm{h}$, the animals were sacrificed, and gastric lesions in the fundic stomach were scored and expressed as ulcer index. L.camara, A.muricata, K.pinnata leaves aqueous extract was administered orally $30 \mathrm{~min}$ prior 
to indomethacin treatment to see the gastroprotective effect. Rabeprazole were administered orally at a dose of $20 \mathrm{mg} / \mathrm{kg}$ body weight respectively.

\section{Assessment of gross mucosal damage}

The lesion in the glandular portion was examined under a $10 \mathrm{x}$ magnifying glass and length was measured using a divider and scale and gastric lesion was scored as follows:

Scoring of ulcer was made as follows:

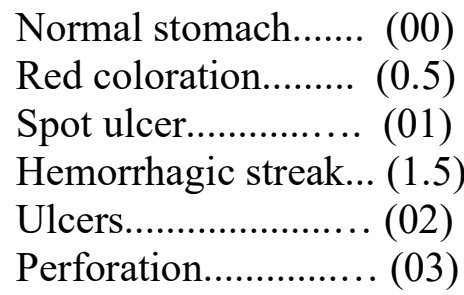

Ulcer index of each animal was calculated by adding the values and their mean values were determined and percentage inhibition was calculated (29).

\section{Formula for Ulcer Protection}

$\%$ Protection $=\underline{(\text { Ulcer index Control }- \text { Ulcer index Test })} \times 100$ No. of Animals

\section{Determination of $\mathrm{pH}$ and volume of gastric juice}

Gastric juice $(1 \mathrm{~mL})$ was diluted with $1 \mathrm{~mL}$ distilled water and was measured using a $\mathrm{pH}$ meter and the volume of gastric juice also measured by measuring tubes.

\section{Free and Total Acidity}

Free and total acidity were determined by titrating with $0.01 \mathrm{~N} \mathrm{NaOH}$ using Topfer'sreagent and phenolphthalein as indicator. The free and total acidity were expressed as $\mu$ equiv/100 g.

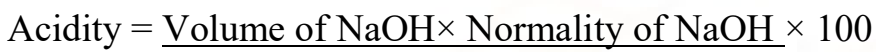

$$
0.1 \mathrm{~N}
$$

\section{RESULTS}

\section{Preliminary phytochemical screening}

The phytochemical screening of the plant extract revealed the presence of various bioactive costituents like alkaloids, flavonoids, saponins and tanins.

\section{Acute Toxicity Study}

The oral acute toxicity study of aqueous extract of L.camara, A.muricata, K.pinnatumWere evaluated according to Organization for Economic Cooperation and Development (OECD) guideline 420 on wistar rats, where the limit test dose of $1000 \mathrm{mg} / \mathrm{kg}$ was used.No mortality observed for 14days.

\section{Immersion of Cold Restrained Stress}

In the present study the anti-ulcer activity of leaves of L.camara, A.muricata, K.pinnatum. Revealed that the minimum ulcer index was observed with Rabeprazole.

Table:1 Effect of L.camara, A.muricata, K.pinnatum leaves aqueous extract gastric juice volume, pH, total acidity, free acidity, total ulcer index and ulcer protection

\begin{tabular}{|c|c|c|c|c|c|c|}
\hline Group & $\begin{array}{c}\text { Gastricjuice } \\
\text { volume in } \\
\text { ml }\end{array}$ & $\begin{array}{c}\text { Gastricjuice } \\
\text { pH }\end{array}$ & $\begin{array}{c}\text { Free } \\
\text { acidity } \\
(\mathbf{m E q} / \mathbf{d l})\end{array}$ & $\begin{array}{c}\text { Total } \\
\text { acidity } \\
(\mathbf{m E q} / \mathbf{d l})\end{array}$ & $\begin{array}{l}\text { TotalUlcer } \\
\text { index }\end{array}$ & $\begin{array}{c}\text { Ulcer } \\
\text { protection(\%) }\end{array}$ \\
\hline Control & $3.78 \pm 0.12$ & $3.1 \pm 0.30$ & $54.6 \pm 0.04$ & $61.35 \pm 0.06$ & $0.01 \pm 0.00$ & 99 \\
\hline $\begin{array}{l}\text { Disease } \\
\text { control }\end{array}$ & $1.3 \pm 0.04$ & $1.4 \pm 0.05$ & $97.87 \pm 0.44$ & $119.2 \pm 0.37$ & $3.65 \pm 0.11$ & 9 \\
\hline $\begin{array}{l}\text { L.camara } \\
150 \mathrm{mg} / \mathrm{kg}\end{array}$ & $1.82 \pm 0.05$ & $2.25 \pm 0.06$ & $51.22 \pm 0.28$ & $59.25 \pm 0.06$ & $2.55 \pm 0.17$ & 36.5 \\
\hline $\begin{array}{l}\text { A.muricata } \\
150 \mathrm{mg} / \mathrm{kg}\end{array}$ & $2.27 \pm 0.07$ & $2.47 \pm 0.04$ & $47.72 \pm 0.07$ & $56.49 \pm 0.30$ & $2.25 \pm 0.06$ & 44.2 \\
\hline $\begin{array}{l}\text { K.pinnata } \\
150 \mathrm{mg} / \mathrm{kg}\end{array}$ & $2.82 \pm 0.05$ & $2.87 \pm 0.08$ & $44.82 \pm 0.04$ & $53.72 \pm 0.08$ & $1.77 \pm 0.07$ & 56.5 \\
\hline $\begin{array}{c}\text { Rabeprazole } \\
20 \mathrm{mg} / \mathrm{kg}\end{array}$ & $3.27 \pm 0.08$ & $3.05 \pm 0.13$ & $39.82 \pm 0.04$ & $50.67 \pm 0.37$ & $0.8 \pm 0.13$ & 80.4 \\
\hline
\end{tabular}


Values are expressed as mean \pm SEM. $P>0.05$ when compared to normal control group by Statistical analysis by One-way ANOVA followed by Dunnett's method.

Fig: 9 Morphological Features of Stomach in Stress Induced Ulcer

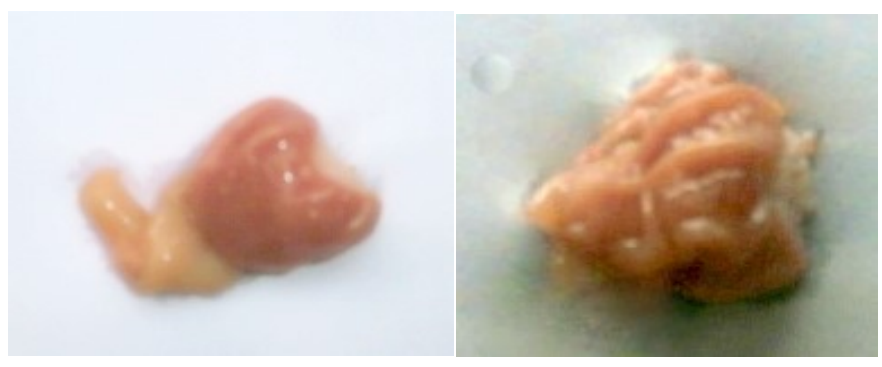

a. Normal control

b. Experimental Control
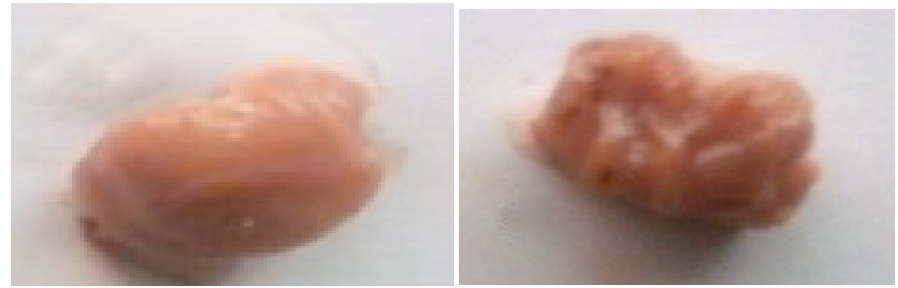

c. L.camara $1000 \mathrm{mg} / \mathrm{kg}$

d. A.muricata $1000 \mathrm{mg} / \mathrm{kg}$

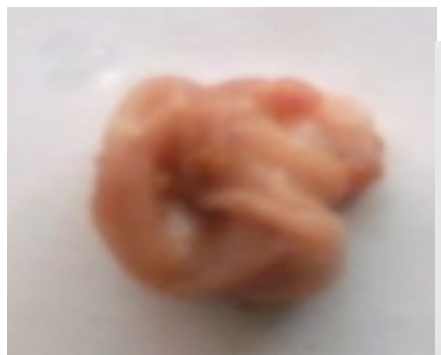

e. K.pinnata $1000 \mathrm{mg} / \mathrm{kg}$ f. Rabeprazole $20 \mathrm{mg} / \mathrm{kg}$

\section{Morphological study of stomach}

In normal group stomach integrity was maintained and appeared normal. In control group severe bleeding, perforation, spot ulcer were observed but, in standard group and extract treated groups, animal showed less ulceration and stomach integrity was maintained.
Fig: 11 Histology of Stomach in Stress induced Ulcer
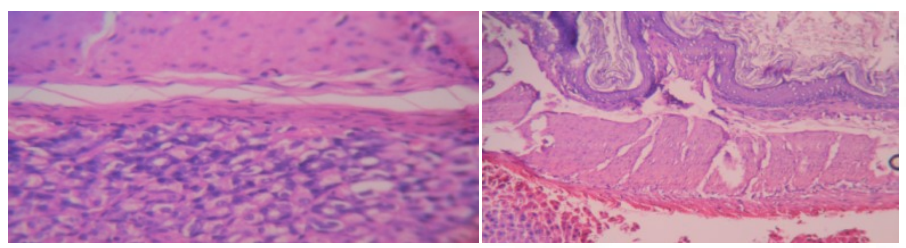

a. Normal control

b. Experimental Control

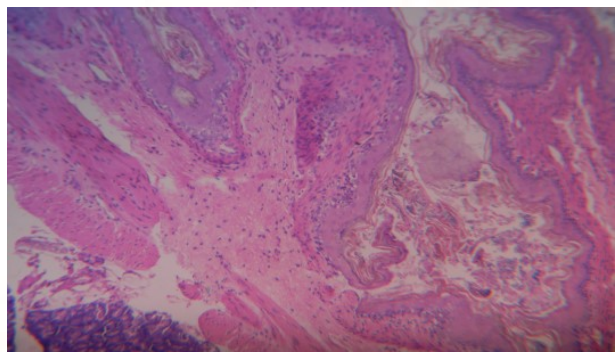

c. L.camara $1000 \mathrm{mg} / \mathrm{kg}$

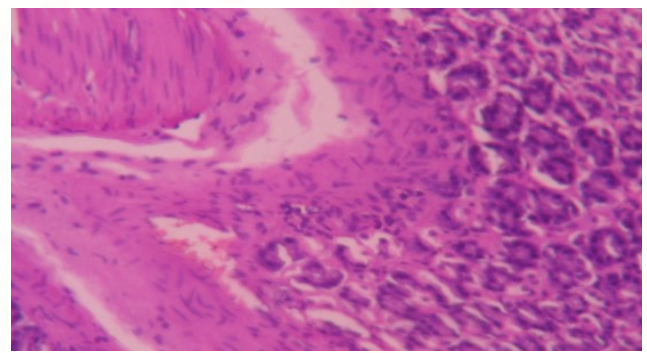

d. A.muricata $1000 \mathrm{mg} / \mathrm{kg}$

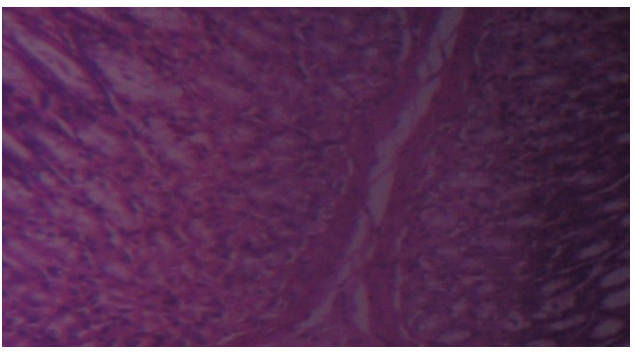

e. K.pinnata $1000 \mathrm{mg} / \mathrm{kg}$

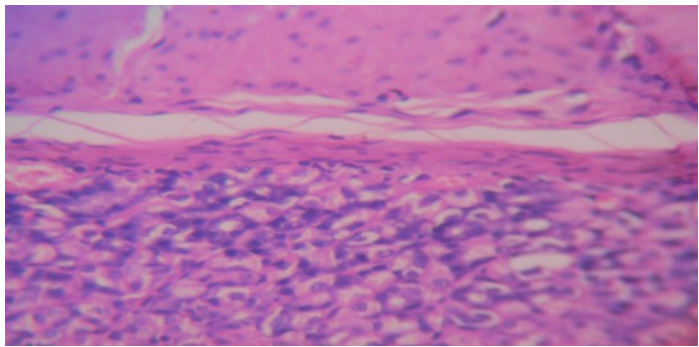

f. Rabeprazole $20 \mathrm{mg} / \mathrm{kg}$ 


\section{Histopathological study}

Histopathological examination of gastric mucosa in the normal control group showed intact gastric mucosa and continuous epithelial surface. Experimental control revealed mucosal ulceration. In L.camara $(1000 \mathrm{mg} / \mathrm{kg})$ group, superficial erosions and few ulcers accompanied with mild inflammatory was observed. In A.muricata $(1000 \mathrm{mg} / \mathrm{kg})$ group, slight ulcer with inflammatory infiltrate and congestion in few areas was observed. In K.pinnata $(1000 \mathrm{mg} / \mathrm{kg})$ group, section revealed intact mucosa with no inflammation. In Rabeprazole $(20 \mathrm{mg} / \mathrm{kg})$ group, showed intact gastric mucosa without any inflammatory.

\section{DISCUSSION}

The peptic ulcer results from an imbalance between aggressive factors and the maintenance of mucosal integrity through the endogenous defense mechanisms (12). To regain the balance, different therapeutic agents are used to inhibit the gastric acid secretion or to boost the mucosal defence mechanisms by increasing mucosal protection, stabilizing the surface epithelial cells or interfering with the prostaglandin synthesis. The causes of gastric ulcer pyloric ligation are believed to be due to stress induced increase in gastric hydrochloric acid secretion and or stasis of acid and the volume of secretion is also an important factor in the formation of ulcer due to exposure of the unprotected lumen of the stomach to the accumulating acid (18).

Cold restraint causes both psychological and physical stress to the rats. The induced stress releases histamine in the stomach, which leads to increased acid secretion and decreased mucus production, ultimately leading to ulcers (17).

Physiologic stress stimulate adenohypophysical axis and causes a concomitant release of endogenous opiates. Stress also produces severe gastric erosion through the activation of central vagal discharge. The endogenous opiates released during stress can cause mucosal congestion by a peripheral mechanism, leading to the development of gastric ulcers. Stress induced ulcers are as a result of autodigestion of gastric mucosal barrier, accumulation of HCL and generation of free radicals (39).

Extensive damage to gastric mucosa by stress leads to increase neutrophil, which are a major source of inflammatory mediators, inhibit gastric ulcer healing by mediating lipid peroxidation through the release of highly cytotoxic and tissue damaging reactive oxygen species such as superoxide, hydrogen peroxide and myeloperoxidase derived oxidants. Suppression of neutrophil infiltration during inflammation enhances gastric ulcer healing.

Various physical and psychological stressors cause gastric ulceration in humans (11), and rat models have been developed to mimic the disease condition in humans. This model employs the restraint technique developed (6) coupled with the cold-water or ordinary-water immersion method (27). The combination of these methods is reported to be synergistic in inducing acute stress lesion in rats (50), arising mainly from physiological discomfort. Gastric ulcers induced by cold-water-restraint stress (CWRS) or cold-restraint stress (CRS) or water-immersion stress (WIS) in rats or mice are known to resemble human peptic ulcers, both grossly and histopathologically (25). The model is widely used and is reported to be useful for assessing or studying the effects of agents/medicines on the healing of ulcers in rats. Stress-induced ulcers manifest as single or multiple mucosal defects. The pathophysiology of stress-induced ulcers is complex.

The ulcers are produced due to the release of histamine, leading to an increase in acid secretion, a reduction in mucus production (24), pancreatic juice reflux, and poor flow of gastric blood (20). Stress also causes an increase in gastrointestinal motility resulting in folds in the stomach (42) that are more susceptible to damage when they come in contact with acid (6). Furthermore, stress has also been found to decrease the quality and amount of mucus adhering to the gastric mucosa. It has been suggested that, in conditions of emotional tension, there is not only a greater destruction of mucus and decreased synthesis of its components, but also a quality change that affects the translation, acylation, and glycosylation of the ribosomal peptides ((42). Implicitly, the stomach wall mucus plays an important role in stress-induced glandular lesions. Increased vagal activity has also been reported to be one of the factors involved in stress-induced ulcers (6). Due to the critical role that mucus plays in protecting the stomach and also enhancing healing in the stomach walls, the model is recommended for use when evaluating mucosal and cytoprotective agents. 
Phytochemical analysis on the leaves aqueous extract gave positive results for flavonoids, alkaloids, saponins, carbohydrate, tanins and triterpens. The obtained results strongly suggest that flavonoids and alkaloids are the major components of the extract and therefore some of the pharmacological effects could be attributed.

Flavonoids are among the cytoprotective materials able to increase mucus, bicarbonate and prostaglandin secretion, strengthening of gastric mucosal barrier and scavenging of free radicals which are very important in preventing ulcerative and erosive lesions of gastrointestinal tract (48).

Flavonoids are polyphenolic compounds that are ubiquitous in nature and are categorized, according to chemical structure, into flavonols, flavones, flavanones, isoflavones, catechins, anthocyanidins and chalcones. The pharmacological activities of flavonoids were closely related to their functional group. In addition, there may be some interference rising from other chemical components present in the extract. Moreover, flavonoids may exert their cell structure protection through a variety of mechanisms; one of their potent effects may be through their ability to increase levels of glutathione, a powerful antioxidant (37).

Flavonoids have anti-inflammatory activity and protect the gastric mucosa against a variety of ulcerogenic agents in different mammalian species (52). Hence, many studies have examined the antiulcerogenic activities of plants containing flavonoids. Plants containing flavonoids were found to be effective in preventing this kind of lesion, mainly because of their antioxidant properties. Recently, the antioxidant activity of flavonois has attracted interest because of the strong evidence that oxidation processes are involved in the mechanisms of several gastric disorders, including ulcerogenesis (28).

The phyto-constituents like flavonoids, tannins, terpenoids, and Saponin have been reported in several anti-ulcer literatures as possible gastro protective agents. Flavonoids, tannins and triterpenes are among the cytoprotective active materials for which anti ulcerogenic efficacy has been extensively confirmed (7). Tannins may prevent ulcer development due to their protein precipitating and vasoconstriction effects. Their astringent action can help precipitating micro proteins on the ulcer site, thereby forming an impervious layer over the lining that hinders gut secretions and protects the underlying mucosa from toxins and other irritants $(5,36)$.

Oral administration of RABI (Rabeprazole) significantly reduced ulcer index, gastric juice free and total acidity and pepcin activity. However, the drug has not produced any significant quantitative change in the mucin content. Rabeprazole was reported to significantly increase the production of mucin (a defense factor) in rats. It prevented or reduced the size of gastric ulcers. rabeprazole caused dose-dependent inhibitiRabeprazole is an inhibitor of the gastric proton pump. It causes dose-dependent inhibition of acid secretion and has a more rapid on of indomethacin-induced ulceration. $\mathrm{R}(+)$-rabeprazole appears to be the major isomer having anti-ulcer activity (8).

The anti-ulcer activity of the leaves aqueous extract of L.camara, A.muricata, K.pinnatum was evaluated against gastric lesions induced by stress.

Treatment with L.camara, A.muricata, K.pinnatum protected the gastric mucosa from damage by increasing the mucin content significantly. Apparently, the free radicals scavenging property of L.camara, A.muricata, K.pinnatum might contribute in protecting the oxidative damage to gastric mucosa.

\section{CONCLUSION}

Herbal products are well thought-out to be symbols of safeguard in comparison to the synthetic product that are regarded as unsafe to human life and environment. While herbs had been priced for their medicinal significance. The three plants extracts and anti- ulcer drug RABI compared. Among these, the anti-ulcer drug Rabeprazole and K.pinnatum were more effective than the L.camara, A.muricata.

\section{REFFERENCE}

1) AlassaneWele, Yanjun Zhang, ChristelleCaux, Jean-Paul Brouard,Jean-Louis Pousset, Bernard Bodo, Annomuricatin C., "A novel cyclohexapeptide from the seeds of Annona muricata", C RChimie, 2004; 7: 981-988. 
2) Anon., “ The useful plants of India”, Publications \& Information Directorate, CSIR, New Delhi, India, 1986.

3) Anoop A., Jegadeesan M., Biochemical Studies on the Anti-Ulcerogenic Potential of HemidesmusIndicus. J Ethnopharmacol. 2003; 84: 149-156.

4) Apak R, Guclu K, Demirata B, et al. Comparative evaluation of various total antioxidant capacity assays applied to phenolic compounds with the CUPRAC assay. Molecules 2007; 12(7): 14961547.

5) Berenguer, B., Sanchez, L.M., Qulilez, A., Lopez barreiro, Galvez, J., Martin, M.J. Protective and antioxidant effects of Rhizophora mangle $\mathrm{L}$. against NSAID-induced gastric lesions. J Ethnopharmacol 2005; Volume 103, Pages 104200.

6) BrodieD.A andH.M. Hanson "A study of the factors involved in the production of gastric ulcers by the restraint technique," Gastroenterology., 1960; vol. 38, pp. 353-360.

7) Borelli, F., Izzo, A.A. The plant kingdom as a source of anti-ulcer remedies. Phytotherapy Research., 2000; Volume 14, pages 581-91.

8) Cao H, Wang M, Jia J, Wang Q, Cheng M., "Comparison of the effects of pantoprazole enantiomers on gastric mucosal lesions and gastric epithelial cells in rats", Health Sci, 2004; 50:1-8.

9) Christophe Gleye, Alain Laurens,ReynaldHocquemiller, Olivier Laprevote, Laurent Serani and Andre Cave, Cohibins A and B., "Acetogenins from roots of Annona muricata", Phytochemistry,1997; 44( 8): pg1541 -1545.

10) Cullen D J, Hawkey G M, Greenwood D C: Peptic ulcer bleeding in the elderly: relative roles of Helicobacter pylori and non-steroidal antiinflammatory drugs. Gut 1997; 41 (4): 459-62.

11) Demirbilek.Surses I.G,SezginN.KaramanA. andurb"uzN.G" "Protective effect of polyunsaturated phosphatidylcholinepretreatment on stress ulcer formation in rats," Journal of PediatricSurgery, vol. 2004; 39, no. 1, pp. 57-62.
12) Dhuley JN. Protective effect of Rhinax, a herbal formation against physical and chemical factors induced gastric and duodenal ulcers in rats. Indian J Pharmacol1999; 31:128-32.

13) Falcao HS, Mariath IR, Diniz MFFM, Batista LM, Barbosa-Filho JM. Plants of the American continent with antiulcer activity. Phytomed 2008; 15: $132-46$.

14) Falk GW., Cecil Essentials of Medicine. 5th Edn.,W.B.Saunders Company, Edinburgh. 2001; 334-343.

15) Ghani A. "Monographs of the recorded medicinal plants", Medicinal Plants of Bangladesh. 2nd ed. Asiatic Society of Bangladesh, 2003;p. 271-272.

16) Glavin GB. Szabo S., Experimental Gastric Mucosal Injury Laboratory Models Reveal Mechanisms of Pathogenesis and New Therapeutic Strategies. FASEB J. 1992; 6: 825831.

17) Glavin GB, Paré WP, Sandbak T, Bakke HK, Murison R. Restraint stress in biomedical research: an update. NeurosciBiobehav Rev 1994;18:223-49.

18) Goulart YC, Sela VR, Obici S, Vanessa J, Martins $\mathrm{C}$, Otobone $\mathrm{F}$ et al. Evaluation of gastric anti-ulcer activity in a hydroethanolic extract from Kielmeyeracoriacea. Braz Arch BiolTechn 2005; 48(1):211-16.

19) Goyal R. K. Elements of Pharmacology, B.S. Shah Prakashan, NewDelhi, India, 17th edition, 2008.

20) Guth P. H. "Gastric blood flowin restraint stress,"TheAmerican Journal of Digestive Diseases., 1972; vol. 17, no. 9, pp. 807-813.

21) Hajrezaie M, Golbabapour S, Hassandarvish P, Gwaram NS, Hadi AH, Ali HM, et al., "Acute toxicity and gastroprotection studies of a new Schiff base derived copper(II) complex against ethanol induced acute gastric lesions in rats", PLosOne, 2012; doi: 10.1371/journal.pone.0051537. 
22) Kent-LioydKC.,Debas HT., Peripheral Regulation of Gastric Acid Secretion. Physiology of the Gastrointestinal Tract. Raven Press, New York. 1994; 1126-1185.

23) Khayum MA, Nandakumar K, Gouda TS, Khalid SM, VenkatRao N, Kumar SMS. Antiulcer activity of stem extract of Tinosporamalabarica(Lamk.)

Pharmacologyonline2009; 1: 885.

24) Kitagawa H. FujiwaraM. and OsumiY. "Effects of waterimmersion stress on gastric secretion and mucosal blood flow in rats," Gastroenterology., 1979; vol. 77, no. 2, pp. 298-302.

25) Konturek P. C. BrzozowskiT.KaniaJ. et al., "Pioglitazone, a specific ligand of peroxisome proliferator-activated receptorgamma, accelerates gastric ulcer healing in rat," EuropeanJournal of Pharmacology., 2003; vol. 472, no. 3, pp. 213220.

26) Kumar SV, Sankar P and Varatharajan R. Antiinflammatory activity of roots of Achyranthesaspera. PharmaceuticalBiology. 47 (10); 2009: 973-975.

27) Levine R. J. "A method for rapid production of stress ulcers in rats," in Peptic Ulcer, C. J. Pfeiffer, 1971; Ed., pp. 92-97,Munksgaard, Copenhagen, Denmark.

28) Magaji RA, Okasha MAM, Abubakar MS, Fatihu MY. Antiulcerogenic and anti-secretory activity of the N-butanol portion of Syzygiumaromaticum in rats. Nigerian J Pharm Sci2007; 6 (2):119-126.

29) Malairajan . P Gopalakrishnan . GNarasimhan . SVeniK.J.KavimaniS.J. Ethnopharmacol, 2007; 110, 348-351.

30) Malfertheiner, F. K. Chan, and K. E. McColl, "Peptic ulcer disease," The Lancet, 2009; vol. 374, no. 9699, pp. 1449-1461.

31) McKenzie RA, Dunster PJ., "Hearts and flowers: Bryophyllum poisoning of cattle", Aust. Vet. J, 1986; 63: 222.

32) Mcquaid KR., Current Medical Diagnosis and Treatment. 1st Edn., Lange Medical
Books/McGraw Hill Company, New York. 2002; 616-621.

33) Miller L C and Tainter M L, Proc. Soc Expt. Biol, Med, 1944; 57-261

34) Muzitano MF, Falcão CAB, Cruz EA, Bergonzi $\mathrm{MC}$, Bilia AR, Vincieri FF, et al., "Oral metabolism and efficacy of Kalanchoepinnata flavonoids in a murine model of cutaneous leishmaniasis", Planta Med, 2009; 75: 307-11.

35) Nayak BS, Marshall JR, Isitor G., "Wound healing potential of ethanolic extract of Kalanchoe pinnata Lam. Leaf-A preliminary study", Indian J. Experim. Biol, 2010; 48: 572-576.

36) Nwafor, P.A., Effrain, K.D., Jack, T.W. Gastroprotective effects of aqueous extract of Khayasenegalensis bark on indomethacin-induced ulceration in rats. West African Journal of PharmacologyandDrugresearch, 1996; volume12, Pages 46-50.

37) O'Byrne DJ, Devaraj S, Grundy SM, Jialal I. Comparison of the antioxidant effects of Concord grape juice flavonoids alpha-tocopherol on markers of oxidative stress in healthy adults. Am J ClinNutr 2002; 76(6):1367-1374.

38) Okwu DE, Nnamdi FU., "Two novel flavonoids from Bryophyllumpinnatumand their antimicrobial Activity", J. Chem. Pharm. Res, 2011;3(2):1-10.

39) Olaleye SB, Farombi EO. Attenuation of indomethacin and $\mathrm{HCI} /$ ethanol-induced oxitative gastric mucosa damage in rats by Kolaviron: A natural biflavonoid of Garcina kola seed.Phytothera Res 2006; 20: 14.

40) Onasanwo SA, Singh N, Olaleye SB, Palit G. Anti-ulcerogenic and proton pump $(\mathrm{H}+, \mathrm{K}+$ ATPase) inhibitory activity of Kolaviron from Garcinia kola Heckel in rodents. Indian $\mathbf{J}$ ExpBiol2011; 49:461-468.

41) Ozsoy N, Candoken E, Akev N. Implications for degenerative disorders: antioxidative activity, total phenols, flavonoids, ascorbic acid, beta-carotene 
and beta-tocopherol inAloe vera. Oxid Med Cell Longev 2009; 2(2): 99-106.

42) Peters M. N. and Richardson C. T. "Stressful life events, acid hypersecretion, and ulcer disease," Gastroenterology., 1983; vol. 84,no. 1, pp. 114119.

43) Rajkumar V et al. Evaluation of cytotoxic potential of Acoruscalamusrhizome. Ethnobotanical Leaflets. 13 (6); 2009: 832-839.

44) Repetto MG, Llesuy SF. Antioxidant properties of natural compounds used in popular medicine for gastric ulcers. Braz J Med Biol Res 2002; 35: 52334.

45) Rezaeizadeh A, Zuki ABZ, Abdollahi M. Determination of antioxidant activity inmethanolic and chloroformic extracts of MomordicaCharantia. Afr J Biotech., 2011; 10 (24): 4932-4940.

46) Ross IA., "Medicinal plants of the world. Chemical constituents, traditional and modernmedical uses", New Jersey, Humana Press, 1999.

47) Sabu MC and Kuttan R. Anti-diabetic activity of medicinal plants and its relationship with their antioxidant property. Journal ofEthnopharmacology. 81 (2); 2002; 155-160.

48) Sachin, S. S. and Archana, R. J. Antiulcer activity of methanol extract of ErythrinaindicaLam. leaves in experimental animals. PharmacognosyResearch., 20091 (6): 396-401.

49) Sastri BN., "The wealth of India", CSIR New Delhi, India. 1962.

50) SenayE. C. and LevineR. J. "Synergism between cold and restraint for rapid production of stress ulcers in rats," Proceedingsof the Society for Experimental Biology and Medicine.,1967; vol. 124, no. 4, pp. 1221-1223.

51) Sidhartha PA, ChandhuriKW., "Antiinflammatory action of Bryophyllumpinnatumleaf extract", Fitoterapia, 1990; 41: 527-533.
52) Shetty BV, Arjuman A, Jorapur A, Samanth R, Yadav SK, Valliammai N, et al. Effect of extract of Benincasahispidaon oxitative stress in rats with Indomethacin-induced gastric ulcers. Indian $\mathrm{J}$ PhysioPharmcol2008; 52(2): 178-182.

53) Supratman UT, Fujita K, Akiyama H, Hayashi A, Murakami H, Sakai K, et al., "Anti-tumor Promoting Activity of Bufadienolides from Kalanchoe pinnata and K. daigremontianabutiflora",BiosciBiotechnolBioche m, 2000; 165: 947-949.

54) Tepperman BL., Jacobson ED., Circulatory Factors in Gastric Mucosal Defense and Repair. Physiology of the Gastrointestinal Tract. Raven Press, New York. 1994; 1331- 1352.

55) Thamotharan G, Sekar G, Ganesh T, Saikatsen, Raja Chakraborty, Senthil.kumar N., "Antiulcerogenic effect of Lantana camara Leaves on in vivo test models in Rats", Asian.Jour. Pharm.Clinical. Res, 2010; 3: 57-60.

56) Torres-Santos ECS, Da Silva AG, Costa APP, Santos APA, Rossi- Bergmann B., "Toxicological analysis and effectiveness of oral Kalanchoe pinnata on a human case of cutaneous leishmaniasis", Phytother Res, 2003; 17: 801-803.

57) Valle P. D. L. "Peptic ulcer diseases and related disorders," in Harrison's Principles of Internal Medicine, E. Braunwald, A. S. Fauci,D. L.Kasper, S. L. Hauser,D. L. Longo, and J. L. Jameson, Eds., 2005; pp. 1746-1762,McGraw-Hill, New York, NY,USA. 